\title{
IATROGENIA EM ENFERMAGEM
}

\author{
Angela Maria Geraldo Pierin* \\ Cilene Aparecida Costardi Ide* \\ Katia Grillo Padilha* \\ Wanda Markievicz**
}

PIERIN, A. M. G.; IDE, C. A. C.; PADILHA, K. G.; MARKIEVICZ, W. Iatrogenia em enfermagem. Rev. Esc. Enf. USP, São Paulo, 17(2):119-125, 1983.

Os autores deste estudo consideram como principal causa da iatrogenia em enfermagem a falta de preparo teórico das enfermeiras. Verificaram o conhecimento de 51 enfermeiras no preparo de medicação. Correlacionaram este conhecimento com a duraşão do curso de graduação em enfermagem e com a experiência prévia das enfermeiras. Nenhuma correlaşão foi encontrada.

\section{INTRODUÇÃO}

$\mathrm{O}$ rápido desenvolvìmento da indústria farmacêutica, a propaganda intensiva dirigida não apenas à classe médica, mas à população de modo geral, através dos veículos de comunicação de massa, sem controle efetivo por parte dos órgãos oficiais responsáveis, tem estimulado o uso abusivo de medicamentos. Acresce que o grande desenvolvimento da tecnologia médica cada vez mais sofisticada, tem contribuido, entre outros fatores, para o aumento significativo da incidência das doenças iatrogênicas.

Para ILLICH (1975) o perigo da iatrogênese, ou seja, da "doença inventada pelo médico", é decorrente do crescente desenvolvimento mórbido da medicina, que poderá conduzir à diminuição da saúde do homem.

A palavra iatrogênese deriva-se do grego e é composta por iatros, que significa médico e gênese, origem. Apesar de ter morfologicamente significado neutro, o termo tem sido empregado largamente para identificar uma ação prejudicial.

Segundo ALVAREZ citado por LACAZ et alii (1980), "doença iatrógena é a doença despertada pelo próprio médico, por um de seus assistentes, pelos farmacêuticos e até pelos enfermeiros".

FERRAZ et alii (1982) referem-se à participação dos enfermeiros na incidência de iatrogenia como sendo decorrente da omissão de doses,

* Enfermeira. Auxiliar de Ensino do Departamento de Enfermagem Médico-Cirúrgica da Escola de Enfermagem da USP - disciplina Enfermagem Médico-Cirúrgica.

* Enfermeira. Auxiliar de Ensino do Departamento de Enfermagem Médico-Cirúrgica da Escola de Enfermagem da USP - disciplinas Saúde da Comunidade e Enfermagem Preventiva e Comunitária. 
administração de medicamento em concentração incorreta, aplicação em horários e vias impróprios, administração de medicamentos não prescritos em pacientes trocados, assim como a aplicação de fármacos errados, decorrentes de substituições indevidas ou de dúvidas na transcrição ou na interpretação da prescrição médica.

Considerando que a incidência desses fatores pode estar relacionada à bagagem de conhecimentos teórico-práticos do enfermeiro, adquirida tanto durante a sua formação como através do exercício profissional, o presente estudo tem como objetivos: verificar, através de provas de seleção, em uma instituição particular a que os enfermeiros foram submetidos:

- o conhecimento teórico dos enfermeiros no que se refere ao preparo de medicação.

- se existe relação entre a duração do curso de graduação em Enfermagem e os conhecimentos teóricos dos candidatos sobre aquela atividade.

- se existe relação entre a experiência hospitalar anterior e os conhecimentos teóricos dos enfermeiros candidatos à admissão no que se refere ao preparo de medicação.

\section{METODOLOGIA}

Os dados analisados no presente estudo foram retirados das provas de seleção para ingresso de enfermeiros em um hospital geral, particular, do município de São Paulo, nos anos de 1979, 1980 e 1981.

Desta população, foram utilizados os dados de 59 candidatos, por serem os únicos, que continham as informações necessárias a este trabalho, ou seja, a prova de seleção comum a todos os candidatos, a ficha cle solicitação de emprego e/ou o "curriculum vitae". Estas fontes visavam a obtenção das variáveis independentes pretendidas: duração do curso de graduação e experiência hospitalar anterior, que poderiam ter influência direta nos conhecimentos relativos ao preparo de medicação.

Foi objeto deste estudo apenas a incidência de acertos e erros na resolução teórica das cinco questões referentes à administração de medicamentos (cálculo de diluição, concentração, preparo da dosagem medicamentosa prescrita e cálculo de gotejamento de soro), diretamente implicados com a iatrogenia em enfermagem.

\section{RESULTADOS E DISCUSSÃO}

Os dados obtidos são apresentados nas tabelas que seguem. 


\section{TABELA 1}

'Distribuição dos candidatos segundo a duração do Curso de Graduação em Enfermagem: Curso Geral e Habilitação

\begin{tabular}{|c|c|c|c|}
\hline \multirow{2}{*}{ duração do curso } & \multicolumn{2}{|c|}{ candidatos } & \\
\hline & $\mathrm{n}^{9}$ & $\%$ & \\
\hline 3 anos & 6 & 10,2 & \\
\hline 4 anos incluindo Habilitação & 29 & 49,1 & 017 \\
\hline 4 anos excluindo Habilitação & 21 & 35,6 & 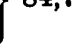 \\
\hline 4 anos mais Habilitação & 3 & 5,1 & \\
\hline TOTAL & 59 & 100,0 & \\
\hline
\end{tabular}

Pela tabela 1 pode-se verificar que predominam os candidatos com cursos de graduação em Enfermagem com duração de 4 anos $(50-84,7 \%)$, dos quais 21 tiveram a Habilitação incluída neste período.

\section{TABELA 2}

Distribuição dos candidatos segundo a experiência hospitalar anterior

\begin{tabular}{|c|c|c|c|}
\hline \multirow{2}{*}{\multicolumn{2}{|c|}{ experiência hospitalar anterior }} & \multicolumn{2}{|c|}{ candidatos } \\
\hline & & $\mathbf{n}^{9}$ & $\%$ \\
\hline $0 \quad 1-$ & 1- $\quad 1$ ano & 48 & 81,4 \\
\hline $1 \quad H$ & 1- 4 anos & 9 & 15,2 \\
\hline 4 & anos e mais & 2 & 3,4 \\
\hline \multicolumn{2}{|c|}{ TOTAL } & 59 & 100,0 \\
\hline
\end{tabular}

Pela tabela 2 verificamos que a maioria dos candidatos ou não tinha experiência hospitalar anterior ou a mesma era inferior a um ano. 


\section{TABELA 3}

Distribuição dos candidatos segundo o número de questões corretas

\begin{tabular}{|c|c|c|}
\hline \multirow{2}{*}{$n^{0}$ de questões corretas } & \multicolumn{2}{|c|}{ candidatos } \\
\hline & $\mathbf{n}^{\mathbf{9}}$ & $\%$ \\
\hline 5 & 5 & 8,5 \\
\hline 4 & 15 & 25,4 \\
\hline 3 & 21 & 35,6 \\
\hline 2 & 15 & 25,4 \\
\hline 1 & 3 & 5,1 \\
\hline TOTAL & 59 & 100,0 \\
\hline
\end{tabular}

A tabela 3 demonstra que do total de candidatos, apenas 8,5\% acertaram todas as questões do teste e que a maior freqüência de acertos $(35,6 \%)$ foi de 3 questões.

Pela Tabela 4 verifica-se que entre os 6 candidatos $(10,1 \%)$ que fizeram Curso de Graduação em 3 anos, 50,0\% acertaram todas as questões, independente de terem tido ou não experiência hospitalar anterior. Dos 29 candidatos $(49,2 \%)$ que cursaram 4 anos incluindo nesse periodo o curso de habilitação, 34,5\% acertaram 2 questões e 34,5\% acertaram 3 questões, tivessem ou não, ambos os grupos, experiência hospitalar anterior. Cabe ressaltar que $20,7 \%$ acertaram 4 questões enquanto que nenhum candidato desse grupo acertou todas as questões da prova. Salienta-se, ainda, que este grupo é constituído por 49,2\% do total de candidatos e que os mesmos, em sua maioria, tinham de zero a um ano de experiência hospitalar anterior. Entre os 21 concorrentes $(35,6 \%)$ com curso de 4 anos sem habilitação, 8 candidatos $(38,0 \%)$ acertaram 3 questões, independente de terem exercido ou não atividades hospitalares anteriores. Verifica-se, também neste grupo, apenas 2 candidatos $(9,4 \%)$ que acertaram a totalidade das questões consideradas básicas e fundamentais para a prática profissional. Este fato é também evidente entre os candidatos que cursaram 4 anos de graduação mais um de habilitação. 


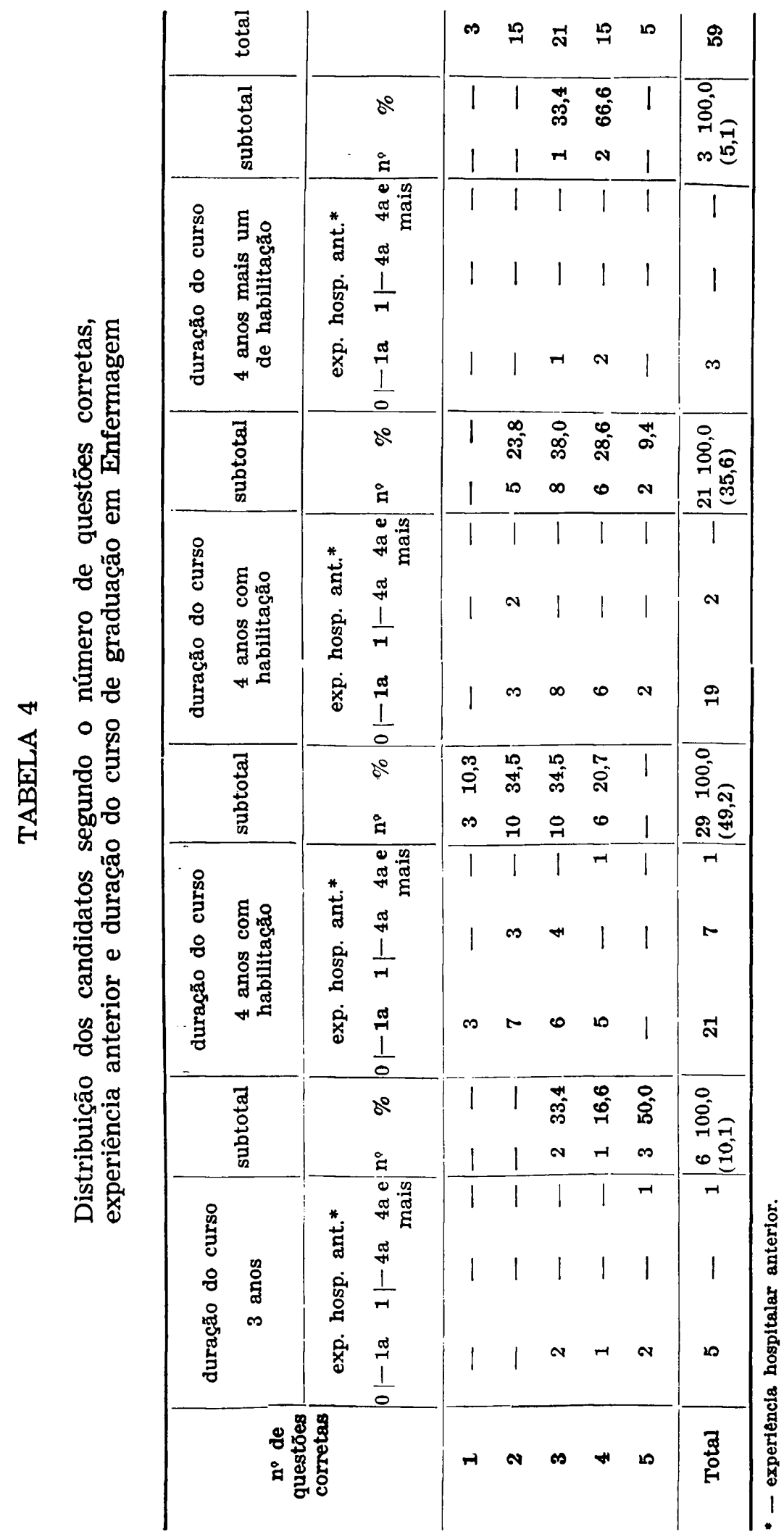




\section{COMENTÅRIOS}

Apesar da população ser pequena e estar restrita a apenas uma instituição hospitalar, a análise dos dados colhidos caracterizou um grupo de enfermeiros que, pelas respostas dadas às questões referentes à diluição, concentração, preparo da dosagem medicamentosa prescrita e cálculo de gotejamento de soro, apresenta deficiências para o desempenho correto dessas atividades na prática profissional.

Verificou-se também que a duração do curso de graduação, assim como a realização ou não da habilitação complementar, parece não ter influenciado significativamente o número de acertos. Tal fato leva a supor a existência de deficiências do ensino pré-universitário do estudante que podem persistir durante a Graduação e a prática profissional se não forem devidamente trabalhadas tanto pelos docentes como pelos enfermeiros responsáveis pela educação continuada.

Assim sendo, acredita-se que os responsáveis pela Educação em Serviço devam utilizar as provas não apenas para a seleção de candidatos mas também para detectar deficiências a serem sanadas.

Quanto à experiência hospitalar anterior, a pequena incidência de enfermeiros com um maior tempo de exercício profissional impossibilitou análise mais detalhada. Observou-se, contudo, que, na faixa compreendida pelos candidatos com zero a 4 anos de trabalho, não houve variação considerável quanto ao número de acertos, permanecendo em torno de apenas 3 questões.

\section{CONCLUSŐES E RECOMENDAÇOES}

Pelo presente estudo conclui-se que:

- os candidatos apresentam deficiência de conhecimentos teóricos no que diz respeito ao preparo de medicações.

- a deficiência de conhecimentos teóricos dos enfermeiros para a resolução das questões sobre o preparo de medicações parecem não estar diretamente relacionados à duração do curso.

- a existência ou não de experiência hospitalar anterior parece ter pouca influência no número de acertos das questões referentes ao preparo de medicação.

Com base nessas conclusões, recomenda-se:

$\left.1^{\circ}\right)$ que este estudo seja ampliado de maneira a propiciar análise mais profunda dos dados;

$2^{\circ}$ ) que as Escolas que ministram Curso de Graduação em Enfermagem reforcem a orientação teórico-prática sobre esse assunto; 
3:) que os programas de Educação em Serviço sejam elaborados considerando inclusive as deficiências detectadas através das provas de seleção, no que se refere ao preparo de medicação, visando com isso a diminuição de incidência de iatrogenias provocadas pela Enfermagem.

PIERIN, A. M. G.; IDE, C. A. C.; PADILHA, K. G.; MARKIEVICZ, W. Iatrogeny in nursing. Rev. Esc. Enf. USP, São Paulo, 17(2):119-125, 1983.

The authors of this study, considering that the main cause of iatrogeny in nursing lies in the lack of the nurses theoretical preparation, analysed the knowledge of 51 nurses in the preparation of medications. They tried to correlate this knowledge with the length of undergraduate program and with previous hospital experience. No correlation was found.

\section{REFERENCIAS BIBLIOGRÁFICAS}

FERRAZ, E. R. et alii. Iatrogenia: implicações para a assistencia de enfermagem. Rev. Esc. Enf. USP, São Paulo, 16(2):165-79, 1982.

ILliCH, I. A. A expropriação da saúde: nêmeses da medicina. 2. ed. Rio de Janeiro, Nova Fronteira, 1975 . $196 \mathrm{p}$.

LACAZ, C. da $S$. et alil. Iatrofarmacogenia. Rio de Janeiro, Guanabara-Koogan, 1980. p.259. 